\title{
SURGICAL INDUCED ASTIGMATISM IN SUPERIOR VS TEMPORAL INCISION IN SMALL INCISION CATARACT SURGERY - A COMPARATIVE STUDY
}

\author{
Adapa Venkata Satish ${ }^{1}$, Renu Sulakhe2, Sayed Aejaz Hussein³, Ch. Ganapathi Swamy4 \\ ${ }_{1}^{1}$ Assistant Professor, Department of Ophthalmology, GSL Medical College and General Hospital, Rajahmundry. \\ ${ }_{2}^{2}$ Associate Professor, Department of Community Medicine, GSL Medical College and General Hospital, Rajahmundry. \\ 32nd Year Postgraduate Student, Department of Ophthalmology, GSL Medical College and General Hospital, Rajahmundry. \\ 4Statistician, Department of Community Medicine, GSL Medical College and General Hospital, Rajahmundry.
}

\begin{abstract}
BACKGROUND
ABSTRACT

Cataract surgery is a boon in itself. With all the possible modalities of cataract surgery, we try to give a normal vision. But Surgically Induced Astigmatism (SIA) is one of the causes of a poor quality of vision. We have studied SIA in 2 different sites of incision in Manual Small Incision Cataract Surgery (SICS).

The objective of this study is to compare the amount of surgically induced astigmatism in superior and temporal incisions in manual small incision cataract surgery.
\end{abstract}

\section{MATERIALS AND METHODS}

Hundred patients were studied. The patients were randomly assigned to any of the two groups. The two groups had 50 patients each. The patients in Group A underwent manual SICS with a superior incision. The patients in Group B underwent manual SICS with a temporal incision. The patients were examined on the post-operative weeks 1, 3 and 6 . The uncorrected and the bestcorrected visual acuity was recorded and a slit-lamp examination and auto-refractometer and keratometry examinations were also done.

\section{RESULTS}

In our study at 6 weeks post-operatively we found almost $80 \%$ people with astigmatism $<0.5 \mathrm{D}$ in temporal section, while there were $20 \%$ people in superior section. We also found that in temporal sclera group, there was reduction of pre-operative ATR astigmatism from $66 \%$ to $64 \%$ and there was no change in pre-operative WTR astigmatism which was $30 \%$ pre- and postoperative (6 weeks).

\section{CONCLUSION}

SICS which is done with a temporal approach provides a better quality of vision due to a significantly less SIA than the superior approach.

\section{KEYWORDS}

Astigmatism, Small Incision Cataract Surgery, Superior Incision, Temporal Incision, Surgically Induced Astigmatism (SIA).

HOW TO CITE THIS ARTICLE: Satish AV, Sulakhe R, Hussein SA, et al. Surgical induced astigmatism in superior vs temporal incision in small incision cataract surgery- a comparative study. J. Evolution Med. Dent. Sci. 2018;7(03):391-393, DOI: $10.14260 /$ jemds/2018/86

\section{BACKGROUND}

Cataract is defined as an opacity in lens capsule or its substance. Cataract surgery is a boon in itself. Small Incision Cataract Surgery (SICS) with posterior chamber intraocular lens implantation is a technique in developing countries like India where free camps are done. SICS is the most favourable technique of surgery.

Astigmatism is a refractive error in which point of light cannot be made to produce a punctate image on the retina by a correcting spherical lens. Significant astigmatism may be visually disabling causing diminution in visual acuity, glare, monocular diplopia, asthenopia and distortion.

'Financial or Other Competing Interest': None.

Submission 11-05-2017, Peer Review 01-01-2018,

Acceptance 08-01-2018, Published 13-01-2018.

Corresponding Author:

Dr. Adapa Venkata Satish,

Assistant Professor, Department of Ophthalmology,

GSL Medical College and General Hospital,

Rajahmundry.

E-mail:banty_has@yahoo.com

DOI: $10.14260 /$ jemds $/ 2018 / 86$

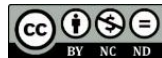

Surgical techniques are being continually modified and improved upon to decrease post-operative astigmatism. In all types of cataract surgeries the incisions which are made on the sclera give rise to scars, thus altering the curvature of the cornea. These scars cause corneal flattening along the meridian of the incision,[1] i.e. the flattening of the cornea occurs ultimately at a direction of right angles to the direction of cataract incision, thus resulting in Surgically Induced Astigmatism (SIA). SIA also depends on the type, length and position of the incision and also on the method of wound closure and suture material used.[2,3] So out of these factors, the major factors responsible for post-operative astigmatism is the location of cataract incision.

Therefore, placing the incision perpendicular to the steep meridian of preexisting astigmatism can reduce postoperative astigmatism. Also, it has been seen that farther the cataract incision from the visual axis, less likely is the effect on the corneal curvature at visual axis.

Temporal scleral location is farther from visual axis and flattening that is less likely to affect the corneal curvature at visual axis, thus causing less post-operative astigmatism.

In view of this, we have endeavoured to compare the astigmatism following conventional superior scleral incision 
and the temporal scleral incision in small incision cataract surgery with posterior chamber intraocular lens implantation.

\section{MATERIALS AND METHODS Study Design}

Hospital based prospective and comparative study of astigmatism induced by superior and temporal incision in manual SICS conducted among 100 patients in the Department of Ophthalmology, GSL Medical College, Rajahmundry.

\section{Study Period}

October 2015 to December 2016.

\section{Inclusion Criteria}

1. Patients diagnosed to have cataract.

2. Patients with clinically normal cornea.

3. Patients in the age group of $50-80 \mathrm{yrs}$.

4. Patients who gave consent to participate in the study.

\section{Exclusion Criteria}

1. Patients with scleral diseases.

2. Patients with connective tissue disorders.

3. Patients unable to co-operate for pre- and post-operative keratometry.

4. Traumatic and paediatric cataracts.

\section{Statistical Analysis}

- All statistical analysis was done by using SPSS software trial version 20.0 and MS Excel 2007.

- Descriptive data was presented as percentages and tabulated.

- Chi-square test was done to assess the association among various categorical variables.

- For all statistical analysis, $\mathrm{P}<0.05$ was considered as statistically significant.

A total of 100 cases of cataract were selected from those attending the OPD. Two groups were created, one for temporal incision and another for superior incision. Random allocation of patients into these groups was done. Fifty patients in each group. Cases selected for study were subjected to detailed history taking and clinical examination and their pre-keratometry readings were recorded. Postkeratometry readings were recorded at 1st week, 3rd week and 6th week. Amplitude of pre-operative and post-operative astigmatism is calculated from difference in keratometric values in steeper and flatter meridians. Amplitude of surgically induced astigmatism is calculated from preoperative and post-operative amplitudes by subtraction method. In superior sclera incision type, a sclera incision of $6.5 \mathrm{~mm}$ was fashioned $3 \mathrm{~mm}$ behind the limbus in superior sclera extending from 11 O'clock to 10 'clock hours. In the temporal sclera incision type, an incision of $6.5 \mathrm{~mm}$ was fashioned $3 \mathrm{~mm}$ behind the limbus extending from 9 0'clock to 11 O'clock hours. A backward cut of $1-1.5 \mathrm{~mm}$, radial to the limbus was made from each edge of the incision. A scleral tunnel was fashioned with a crescent blade. The incision extended approximately $1 \mathrm{~mm}$ into the cornea. The dissection was carried out towards the limbus on both sides to create a funnel shaped "pocket." Anterior chamber was entered with the keratome and then formed with viscoelastic. Anterior capsulotomy was performed with a bent 26-gauge needle. Hydrodissection was done. The incision was then extended, and the nucleus was delivered out by sandwich method. Cortical aspiration was done using Simcoe cannula. Posterior chamber intraocular lens (PCIOL) was inserted in all cases. The anterior chamber was then reformed with balanced salt solution. For simplification of analyses, all astigmatic changes (pre-operative and post-operative) were studied only in the vertical or horizontal axes (only at $90^{\circ}$ or $180^{\circ}$ ). If readings were oblique they were regarded as being with (at $90^{\circ}$ ) or against (at $180^{\circ}$ ) the rule, depending on their values (within $30^{\circ}$ ) proximity with the corresponding vertical or horizontal axis.

\section{Consent}

Written informed consent was taken from the study participants. Confidentiality of the information is maintained by blinding the study participant's name.

\section{RESULTS}

\begin{tabular}{|c|c|c|c|}
\hline Age in Years & Males & Females & Total \\
\hline 51 to 60 & 31 & 29 & 60 \\
\hline 61 to 70 & 17 & 15 & 32 \\
\hline 71 to 80 & 4 & 4 & $\mathbf{8}$ \\
\hline \multicolumn{2}{|c|}{ Table 1. Age Distribution of Cataract } \\
\hline
\end{tabular}

\begin{tabular}{|c|c|c|c|}
\hline Diopters & Temporal & Superiorly & Total \\
\hline$<0.5$ & $27(79.41 \%)$ & $7(20.58 \%)$ & 34 \\
\hline$<0.6-1.0$ & $14(70.00 \%)$ & $6(30.00 \%)$ & 20 \\
\hline $1.1-1.5$ & $3(21.41 \%)$ & $11(78.57 \%)$ & 14 \\
\hline $1.6-2.0$ & $2(13.33 \%)$ & $13(86.66 \%)$ & 15 \\
\hline $2.1-2.5$ & $4(28.57 \%)$ & $10(71.42 \%)$ & 14 \\
\hline$>2.5$ & $0(0 \%)$ & $3(100 \%)$ & 3 \\
\hline
\end{tabular}

Table 2. Surgically Induced Astigmatism in the Temporal and Superior Scleral Incision at $6^{\text {th }}$ Post-operative Week $\alpha^{2}=33.2, \mathrm{P}=0.0000$

There are almost $80 \%$ people with astigmatism $<0.5 \mathrm{D}$ in temporal section, while in superior incision there are $20 \%$ patients. As the astigmatism increased the percentage reduced in temporal section, while in superior sclera the percentage increased.

The eyes that underwent temporal scleral incision $(n=50)$ showed $>2.5 \mathrm{D}$ astigmatism in $0 \%$ cases at 6 th post-operative week. In comparison to this, $6 \%$ of superior scleral incision $(n=50)$ showed up same level of astigmatism.

\begin{tabular}{|c|c|c|c|c|c|c|c|c|}
\hline \multirow{3}{*}{ Period } & \multicolumn{4}{|c|}{ Temporal Scleral } & \multicolumn{4}{c|}{ Superior Scleral } \\
\cline { 2 - 10 } & \multicolumn{2}{|c|}{ ATR } & \multicolumn{2}{c|}{ WTR } & \multicolumn{2}{c|}{ ATR } & \multicolumn{2}{|c|}{ WTR } \\
\cline { 2 - 9 } & No & $\mathbf{\%}$ & No & $\%$ & No & $\%$ & No & $\%$ \\
\hline Pre-operative & 33 & 66 & 15 & 30 & 35 & 70 & 10 & 20 \\
\hline $\begin{array}{c}\text { 1st post-op } \\
\text { week }\end{array}$ & 32 & 64 & 12 & 24 & 38 & 76 & 11 & $\mathrm{i} 22$ \\
\hline $\begin{array}{c}\text { 3rd post-op } \\
\text { week }\end{array}$ & 29 & 58 & 11 & 22 & 40 & 80 & 4 & 8 \\
\hline $\begin{array}{c}\text { 6th post-op } \\
\text { week }\end{array}$ & 32 & 64 & 15 & 30 & 42 & 84 & 7 & 14 \\
\hline
\end{tabular}

Table 3. Decay of Mean Astigmatism in Temporal Scleral and Superior Scleral Incision as compared to Pre-operative and Post-operative Weeks

In our study in the temporal scleral group there was reduction of pre-operative 'against-the-rule' astigmatism 
from $66 \%$ to $64 \%$, and there was no change in 'with-the-rule' astigmatism of pre-operative (30\%) and 6 weeks postoperative which is also $30 \%$. However, decay of mean astigmatism superior scleral group showed a distinct increase in ATR from $70 \%$ to $84 \%$ at 6 weeks postoperatively. Pre-operative WTR reduced from $20 \%$ to $14 \%$ post-operatively. ATR astigmatism in both groups is explained by superior incision, that is astigmatism after cataract extraction is generally of the against-the-rule variety, which is caused by some degree of flattening of the corneal meridian at a right angle to the direction of the incision. When the incision is made above, in its usual location, a postoperative flattening of the vertical meridian results. Hennig A et al in 2003 reported data of 500 eyes, in which SICS was performed. Six weeks post-operatively, $85.5 \%$ of eyes had against-the-rule astigmatism, which is comparable to our study.[5]

Reddy et al in 2007 studied the astigmatism induced by superior incisions in manual SICS and in scleral tunnel phacoemulsification surgery. They found a significant against-the-rule shift in astigmatism in the Phacoemulsification group and the manual SICS superior incision group, which is comparable to our study.[6] Gokhale et al studied mean surgically induced astigmatism in superior incision in manual SICS with visco expression. Mean astigmatism induced by surgery was $1.28 \mathrm{D}$, which is comparable to our study.[7]

Surgically induced astigmatism of $<1 \mathrm{D}$ was found in $82 \%$ cases from temporal scleral group, whereas only $26 \%$ cases from superior scleral group had < 1D SIA in our study. This implies that temporal scleral incision induces less astigmatism when compared to superior scleral incision. Temporal scleral incision give a substantial improvement in surgical exposure, especially in patients with deep set eyes or prominent eyebrows. George et al in 2005 compared SIA following MSICS and Phacoemulsification (PE) in eyes with nuclear sclerosis of grade 3 or less. Mean SIA was 1.17D in the SICS group and 0.77D in the Phacoemulsification group, which is comparable to our study.[8] Suzuki $\mathrm{R}$ et al prospectively examined the induction and spontaneous regression of corneal astigmatism from pre-operative against-the-rule astigmatism in Kelman Phacoemulsification (KPE) in 618 patients and extracapsular cataract extraction (ECCE) in 192 patients. They found that post-operative against-the-rule astigmatism was more frequent after KPE, which is comparable to our study. ${ }^{[9]}$

\section{DISCUSSION}

The study was carried out on 100 patients with 50 patients undergoing SICS by temporal sclera incision and other 50 patients by superior sclera incision. Out of these $100,52 \%$ males and $48 \%$ females were selected. Grouped by age about $48 \%$ were from 51 - 60 years' age group. The findings correspond to the study of Murthy GV, Gupta SK, Bachani D, Jose R and John $\mathrm{N}$ using the age-specific data for those aged 50 years and above. It was observed that the prevalence of blindness at different age cohorts above the age of 50 years changed over the three decades with a peak in cataract blindness prevalence rates in 1989 .
The prevalence of blindness (presenting vision $<20 / 200$ ) was observed to be $8.5 \%$ [95\% CI: 8.1 - 8.9] in the recent survey. It appears that there is a declining trend over the period 1989 - 2001. Extrapolating the observations to the entire country it was estimated that in 2001, there were 7.75 million individuals whose blindness could be attributed to cataract and this would increase to 8.25 million by 2020.[4]

\section{CONCLUSION}

This study shows that there is a significant rise in ATR astigmatism in patients who underwent superior scleral incision as compared to ATR astigmatism in temporal scleral incision where the number of patients were maintained (in fact 1 patient was astigmatic neutral). Temporal scleral incision is more advantageous than superior scleral incision in astigmatically neutral patients, patients with 'against-therule' astigmatism, patients with 'with-the-rule' astigmatism upto $<1 \mathrm{D}$ and superior scleral incision is preferred only if 'with-the-rule' astigmatism is $>1 \mathrm{D}$.

\section{REFERENCES}

[1] Merriam JC, Zheng L, Meriam JE, et al. The effect of incisions for cataract on corneal curvature. Ophthalmology 2003;110(9):1807-13.

[2] Vazquez LA, Panesso JL. Surgically induced astigmatism. A comparison of different cataract incisions and closures. P R Health Sci J 1993;12(2):99103.

[3] Levy JH, Pisacano AM, Chadwick K. Astigmatic changes after cataract surgery with $5.1 \mathrm{~mm}$ and $3.5 \mathrm{~mm}$ sutureless incisions. J Cataract Refract Surg 1994;20(6):630-3.

[4] Murthy GV, Gupta SK, Bachani D, et al. Current estimates of blindness in India. Br J Ophthalmol 2005;89(3):257-60.

[5] Hennig A, Kumar J, Yorston D, et al. Sutureless cataract surgery with nucleus extraction: outcome of a prospective study in Nepal. Br J Ophthalmol 2003;87(3):266-70.

[6] Reddy B, Raj A, Singh VP. Site of incision and corneal astigmatism in conventional SICS versus phacoemulsification. Ann Ophthalmol 2007;39(3):209-16.

[7] Gokhale NS, Sawhney S. Reduction in astigmatism in manual small incision cataract surgery through change of incision site. Indian J Ophthlmol 2005;53(3):201-3.

[8] George R, Rupauliha P, Sripriya AV, et al. Comparison of endothelial cell loss and surgically induced astigmatism following conventional extracapsular cataract surgery, manual small-incision surgery and phacoemulsification. Ophthalmic Epidermol 2005;12(5):293-7.

[9] Suzuki R, Kurimoto S. Similarities and differences between the Kelman phacoemulsification and extracapsular cataract extraction procedure in the spontaneous regression of corneal astigmatism from against the rule astigmatism. Ophthalmic Res 1992;24(3):134-41. 